\title{
Effects of Anodic Buffer Layer in Top-Illuminated Organic Solar Cell with Silver Electrodes
}

\author{
Tien-Lung Chiu, Himadri Mandal, Mi Zhang, Shun-Po Yang, and Ya-Ting Chuang
}

Department of Photonics Engineering, Yuan Ze University, Taoyuan 32003, Taiwan

Correspondence should be addressed to Tien-Lung Chiu; tlchiu@saturn.yzu.edu.tw

Received 19 July 2013; Accepted 16 September 2013

Academic Editor: Stefano Caramori

Copyright (C) 2013 Tien-Lung Chiu et al. This is an open access article distributed under the Creative Commons Attribution License, which permits unrestricted use, distribution, and reproduction in any medium, provided the original work is properly cited.

An efficient ITO-free top-illuminated organic photovoltaic (TOPV) based on small molecular planar heterojunction was achieved by spinning a buffer layer of poly(3,4-ethylenedioxythiophene):poly(styrenesulfonate) (PEDOT:PSS), on the $\mathrm{Ag}^{-\mathrm{AgO}_{x}}$ anode. The PEDOT:PSS thin film separates the active layer far from the Ag anode to prevent metal quenching and redistributes the strong internal optical field toward dissociated interface. The thickness and morphology of this anodic buffer layer are the key factors in determining device performances. The uniform buffer layer contributes a large short-circuit current and open-circuit voltage, benefiting the final power conversion efficiency (PCE). The TOPV device with an optimal PEDOT:PSS thickness of about $30 \mathrm{~nm}$ on $\mathrm{Ag}_{-} \mathrm{AgO}_{x}$ anode exhibits the maximum PCE of 1.49\%. It appreciates a 1.37-fold enhancement in PCE over that of TOPV device without buffer layer.

\section{Introduction}

Organic photovoltaic (OPV) cells based on a small molecular planar heterojunction have attracted much attention since Tang reported the first efficient device in 1986 [1]. At present, the power conversion efficiency (PCE) of OPV cells is less than that of inorganic solar cells $[2,3]$. However, OPV is a promising candidate for the next generation renewable power source because of its easily tunable optical and electrical properties, simple process, flexible application, and low cost [4-7]. The continuous improvement of PCE has focused on material development, interface modification, structural engineering, and absorption enhancement [8-11]. In addition, there is an increasing trend towards the indiumtin-oxide- (ITO-) free devices because of the potential indium shortages and flexible applications [12-15]. OPV plays a capital role in the concept of flexibility applied to mass production by roll-to-roll process [16-18]. Hence, the interface modification between organic layer and substitute anode is an important factor affecting device performance [19]. Various materials are suitable for use as the anode, including aurum $(\mathrm{Au})[20]$, aluminum $(\mathrm{Al})[21]$, silver $(\mathrm{Ag})[19,22]$, and poly(3,4-ethylenedioxythiophene):poly(styrenesulfonate) (PEDOT:PSS) $[4,23]$.

In our previous reports $[24,25]$, we used $\mathrm{Ag}$ film as the anode and cathode to obtain an efficient top-illuminated organic photovoltaic (TOPV) device. However, many studies indicated that metal-induced exciton quenching degrades the number of excitons by nonradiative energy transfer to the metal [26-28]. For OPV device without anodic or cathodic buffer layer, the exciton quenching occurs in active layer close to metallic anode or cathode, leading to the demoted PCE [29-31]. The strength of exciton quenching depends on the exciton drift-length from formation to the donor/acceptor dissociated interface and the distance between exciton and quencher. It can be foreseen that the metal-induced exciton quenching effects in planar heterojunction OPV is stronger than that in bulk heterojunction one, because of the longer drift-length. Currently, bathocuproine (BCP) or 4,7diphenyl-1, 10-phenanthroline (BPhen), and so forth become an essential cathodic buffer layer to prevent the cathodic quenching to achieve the efficient planar heterojunction OPV device. Hence, to further upgrade the PCE of our TOPV device with Ag anode, the anodic buffer layer to separate 
the active layer far from anode and so prevent the anodic metal quenching is out of necessity.

Several metal oxides used to be buffer layer were reported to induce exciton quenching, for example, molybdenum trioxide $\left(\mathrm{MoO}_{3}\right)$ [32], calcium oxide $(\mathrm{CaO})$ [33], tin oxide ( $\left.\mathrm{SnO}\right)$ [34], and so forth. Hence, the high conductive polymeric thin film, PEDOT:PSS, is considered to be the anodic buffer layer that alleviates the exciton quenching in our TOPV devices. Thus, a great enhancement in short-circuit current $\left(J_{\mathrm{sc}}\right)$ of the TOPV device could be anticipated by using the anodic and cathodic buffer layers at the same time to prevent exciton quenching.

In this paper, we investigate the optimization of the optical-electrical performance of a TOPV device to obtain the maximal PCE by utilizing a series of anodic buffer layers fabricated at various spin speeds. By characterizing these buffer layers, their thicknesses and surface morphologies were found to be important parameters that affect the optical field distribution and carrier dynamics inside device and then determine the final device performance.

\section{Experiment}

The basic layer configuration of TOPV follows that in our previous report, comprising a glass substrate/ $\mathrm{Ag}-\mathrm{AgO}_{x}$ $(100 \mathrm{~nm}) / \mathrm{PEDOT}: \mathrm{PSS}$ (0 to $7000 \mathrm{rpm}) /$ copper phthalocyanine $(\mathrm{CuPc} 20 \mathrm{~nm}) /$ fullerene $\left(\mathrm{C}_{60} 40 \mathrm{~nm}\right) / \mathrm{BCP}(7 \mathrm{~nm}) /$ $\mathrm{Ag}(12.5 \mathrm{~nm}) /$ naphthylphenylbiphenyldiamine (NPB $40 \mathrm{~nm}$ ) [25], where $\mathrm{CuPc}$ is electron donor layer, $\mathrm{C}_{60}$ is electron acceptor layer, BCP is exciton block layer to prevent the cathodic quenching, and NPB is capping layer to have more incident photons. Natively, Ag with low work function $4.2 \mathrm{e.V}$ is suitable for electron collection as cathode and its film thickness determines the optical behaviors, highly reflection or semitransparence. $\mathrm{AgO}_{x}$ was formed on the surface of thick Ag film using UV-Ozone (Jelight mode: 42) for $45 \mathrm{sec}$ to raise the work function for anode application. In our previous work, we disclosed that $45 \mathrm{sec}$ UV-Ozone treatment was the optimal parameter for the Ag anode of TOPV. In fabricating the buffer layer, PEDOT:PSS was spun onto the $\mathrm{Ag}-\mathrm{AgO}_{x}$ anode at $500 \mathrm{rpm}$ for $10 \mathrm{sec}$, and then at 1000 to $8000 \mathrm{rpm}$ for $20 \mathrm{sec}$. The physical properties of these buffer layers were sequentially characterized by dynamic force microscope (DFM: SEIKO SPA400), water contact angle analysis, photoelectron spectrometer (Riken Keiki AC-2), and spectrometer (Hitachi U4100). Apart from PEDOT:PSS layer, the organic thin films and $\mathrm{Ag}$ films were deposited by a multisource thermal evaporator under high vacuum $5 \times 10^{-6}$ and $2 \times$ $10^{-5}$ Torr, respectively. The active area of each cell was $4 \mathrm{~mm}^{2}$ defined by the anode and cathode mask cross-section. These devices were carefully encapsulated in a glovebox. Their dark/illuminated current densities $(J)$ versus voltage $(V)$ curves were measured using a source meter (Keithley 2400) without/with an AM 1.5 G 1-sun solar simulator (Newport 91195A). We also employed a system comprising a solar simulator (Newport 66983), a monochromator (Newport 74045), a lock-in amplifier (Stanford Research SR830), a chopper (Stanford Research SR540) and some optical components, to

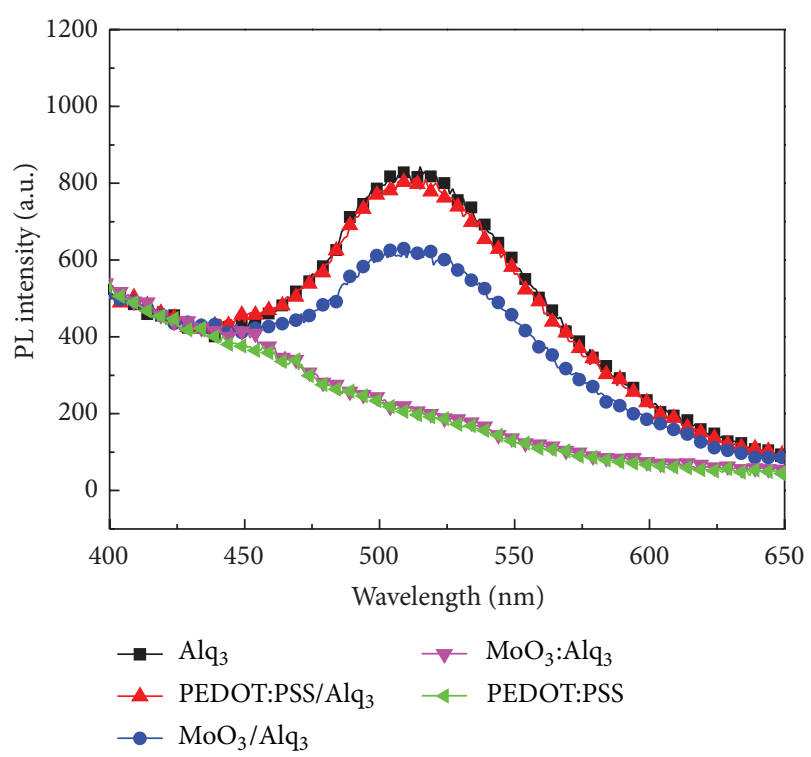

Figure 1: Photoluminescence spectra of five thin films: $\mathrm{Alq}_{3}$, PEDOT:PSS, PEDOT:PSS/Alq ${ }_{3}$, molybdenum trioxide $\mathrm{MoO}_{3} / \mathrm{Alq}_{3}$, and $\mathrm{MoO}_{3}: \mathrm{Alq}_{3}(1: 10)$.

measure their external quantum efficiency (EQE) spectra. In addition, the refractive index and absorption coefficient of the each single thin film were measured with the use of a ellipsometer (Raditech SE-950).

\section{Results and Discussions}

To prove that the exciton quenching effect induced by metal oxide and it can be neglected by using PEDOT:PSS, we fabricated five thin films on glass substrates such as $\mathrm{Alq}_{3}(10 \mathrm{~nm})$, PEDOT:PSS $(20 \mathrm{~nm})$, PEDOT:PSS $(20 \mathrm{~nm}) / \mathrm{Alq}_{3}(10 \mathrm{~nm})$, and $\mathrm{MoO}_{3}(1 \mathrm{~nm}) / \mathrm{Alq}_{3}(10 \mathrm{~nm}), \mathrm{MoO}_{3}$ doped $\mathrm{Alq}_{3}$ (doping ratio in volume $1: 10,11 \mathrm{~nm})$ to measure their photoluminescence (PL) spectra as shown in Figure 1, using spectrometer (Hitachi F4500) with the fixed excitation wavelength of $350 \mathrm{~nm}$. One can see that $\mathrm{Alq}_{3}$ and PEDOT:PSS/Alq ${ }_{3}$ show the almost identical PL intensity. It means that the energy transfer between PEDOT:PSS and excitons in $\mathrm{Alq}_{3}$ layer is negligible. Less exciton quenching effect resulting from PEDOT:PSS can be detected. However, the $\mathrm{MoO}_{3} / \mathrm{Alq}_{3}$ shows the decayed PL intensity due to exciton quenching effect [32]. A number of excitons in $\mathrm{Alq}_{3}$ layer are quenched by $\mathrm{MoO}_{3}$, especially their position closed to $\mathrm{MoO}_{3}$. The considerable exciton quenching can be observed when $\mathrm{MoO}_{3}$ doped into $\mathrm{Alq}_{3}$ layer because the distances between $\mathrm{MoO}_{3}$ atoms and excitons are very short, corresponding to the strongest nonradiative energy transfer between them. Reasonably, its PL intensity is almost naught comparing to that of the pure PEDOT:PSS film. It means that $\mathrm{MoO}_{3}$ does actuate the exciton quenching effects, whereas PEDOT:PSS does not.

Good surface wettability of anode substrate is a basic requirement for the following uniform film deposition [35]. The wetted substrate corresponding to the small static water contact angle benefits the qualified film deposition in atomic 


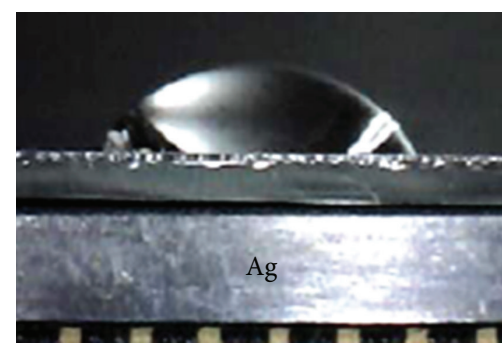

(a)

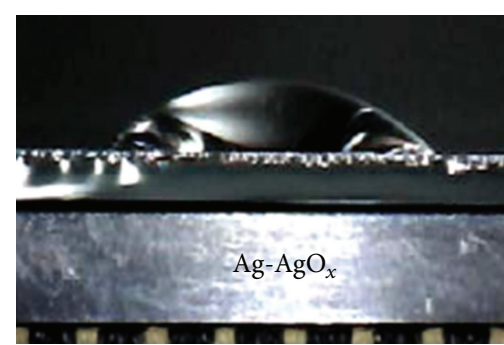

(b)

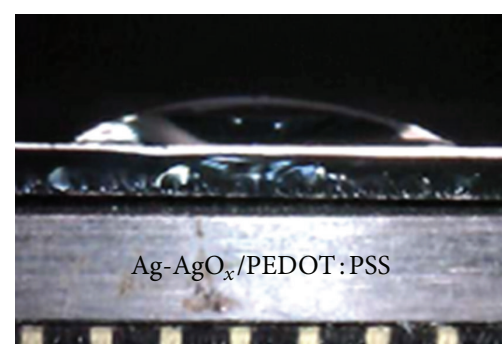

(c)

Figure 2: Static water contact angle on the surface of $\mathrm{Ag}, \mathrm{Ag}-\mathrm{AgO}{ }_{x}, \mathrm{Ag}-\mathrm{AgO} \mathrm{O}_{x} / \mathrm{PEDOT}$ :PSS thin films is $56^{\circ}, 48^{\circ}$, and $31^{\circ}$, respectively.

layer by layer without aggregated islands. There is an agreement on that the organic film deposition on the wetter substrate exhibits the higher carrier mobility, less defect formation, and smoother surface roughness and is good for device performance [35-37]. Figure 2 shows photos for the static water contact angle on the surface of $\mathrm{Ag}, \mathrm{Ag}-\mathrm{AgO}_{x}$, and $\mathrm{Ag}-\mathrm{AgO}_{x} / \mathrm{PEDOT}$ :PSS thin films, used to assess surface wettability. The original Ag film surface is hydrophobic and exhibits a large water contact angle of $56^{\circ}$. After $45 \mathrm{sec}$ UVOzone treatment, the water contact angle a little reduces to $48^{\circ}$ due to the generation of $\mathrm{AgO}_{x}$ on the $\mathrm{Ag}$ surface. There is $\pm 1^{\circ}$ and $\pm 2^{\circ}$ uncertainty in the contact angle on the different $\mathrm{Ag}$ and $\mathrm{Ag}-\mathrm{AgO}$ film surfaces, respectively. To improve further the anodic surface wettability, we coated the anode surface with PEDOT:PSS. UV-Ozone treatment of Ag surface is helpful for the sequential PEDOT:PSS coating to avoid film breakage, because the contact angle of PEDOT:PSS on bare Ag surface is very large [38]. For example, forming a PEDOT:PSS at $5000 \mathrm{rpm}$ provides the conspicuous decease in water contact angle to $31^{\circ}$ as shown in Figure 2. The average water contact angle on various PEDOT:PSS surfaces fabricated at the spin speed of 1000 to $8000 \mathrm{rpm}$ is $30.1^{\circ} \pm 3^{\circ}$. This implies that PEDOT:PSS lamination easily transforms the hydrophobic $\mathrm{AgO}_{x}$ surface to be hydrophilic. In addition, the work function of $\mathrm{Ag}, \mathrm{Ag}-\mathrm{AgO}$, and $\mathrm{Ag}-\mathrm{AgO}_{x} / \mathrm{PEDOT}$ :PSS thin films were $4.16,4.9$, and $5.1 \mathrm{eV}$, respectively. Hence, the fabrication of $\mathrm{Ag}-\mathrm{AgO}_{x} / \mathrm{PEDOT}$ :PSS anode provides good wettability and high work function, suitable for organic layer deposition.

We characterized layer thickness and surface roughness for the various PEDOT:PSS films as shown in Figure 3. As coating speed increased, the thickness of PEDOT:PSS films thinned due to the greater centrifugal force. The figure shows that film thickness fabricated at $1000,3000,5000$, and $7000 \mathrm{rpm}$ were 59.7, 39.8, 29, $11.9 \mathrm{~nm}$, respectively. Under our coating process, the uniformity of film thickness was greater than $90 \%$ while the spin speed is greater than $3000 \mathrm{rpm}$. Distinctively, the uniformity of film thickness less than $70 \%$ was observed as spin speed less than $2000 \mathrm{rpm}$. The average roughness $\left(R_{a}\right)$ of $5 \times 5 \mu \mathrm{m}^{2}$ scanning area dwindles as spin speed grows from $1000 \mathrm{rpm}$ to $5000 \mathrm{rpm}$, and then $R_{a}$ gets large as the spin speed over $5000 \mathrm{rpm}$. The $R_{a}$ curve shows two distinct tendencies with a demarcation at $5000 \mathrm{rpm}$, beyond which speed, defects appear on the PEDOT:PSS surface. Two inserted DFM photos in Figure 3 exhibit the

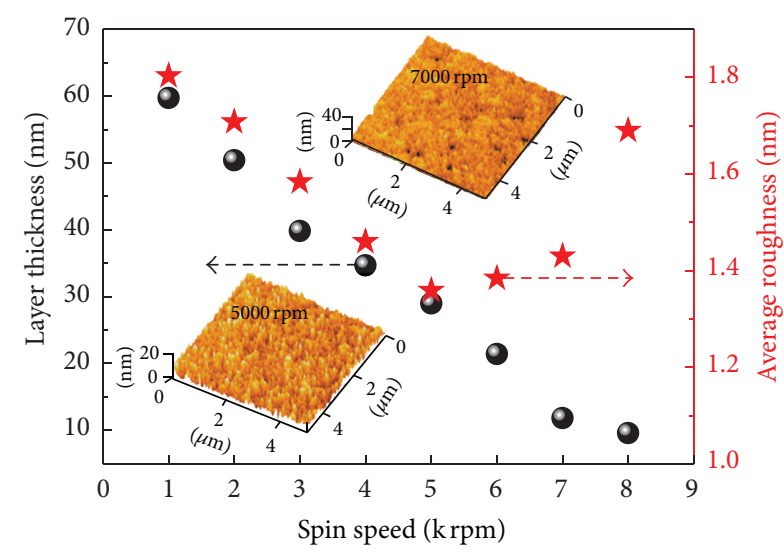

- Thickness

FIGURE 3: Layer thickness and average roughness for various PEDOT:PSS films fabricated at 1000 to $8000 \mathrm{rpm}$ on $\mathrm{Ag}-\mathrm{AgO}_{x}$ anode. The inset DFM photos show the surface of 5000 and $7000 \mathrm{rpm}$ films.

smooth surface at $5000 \mathrm{rpm}$, and the appearance of holes on the surface at $7000 \mathrm{rpm}$. This defect formation results from an interaction between the weak surface tension of PEDOT:PSS solution and the strongly hydrophobic $\mathrm{AgO}_{x}$ surface. Hence, a PEDOT:PSS film thickness of less than $20 \mathrm{~nm}$ is hard to obtain with perfect surface using $\mathrm{AgO}_{x}$ substrate because the surface tension of PEDOT:PSS solution is not strong enough to allow spreading on the hydrophobic $\mathrm{AgO}_{x}$ surface. This problem can be anticipated to be much greater for the bare Ag substrate.

Figure 4 presents the wavelength dependent reflective index $(n)$ and absorption coefficient $(k)$, as well as simulated optical field distribution inside the TOPV devices with/without $30 \mathrm{~nm}$ PEDOT:PSS layer. The involved refractive indexes and absorption coefficients of the organic layers such as PEDOT:PSS, $\mathrm{CuPc}, \mathrm{C}_{60}$, and $\mathrm{BCP}$ were individually measured from a fixed layer thickness of $50 \mathrm{~nm}$ utilizing an ellipsometer (Raditech SE-950) as shown in Figure 4(a). Furthermore, the simulation program was using the optical model of transfer matrix to illustrate the optical field distribution inside TOPV as shown in Figures 4(b) and 4(c) [3941]. Both simulate diagrams show two divisions in the optical 


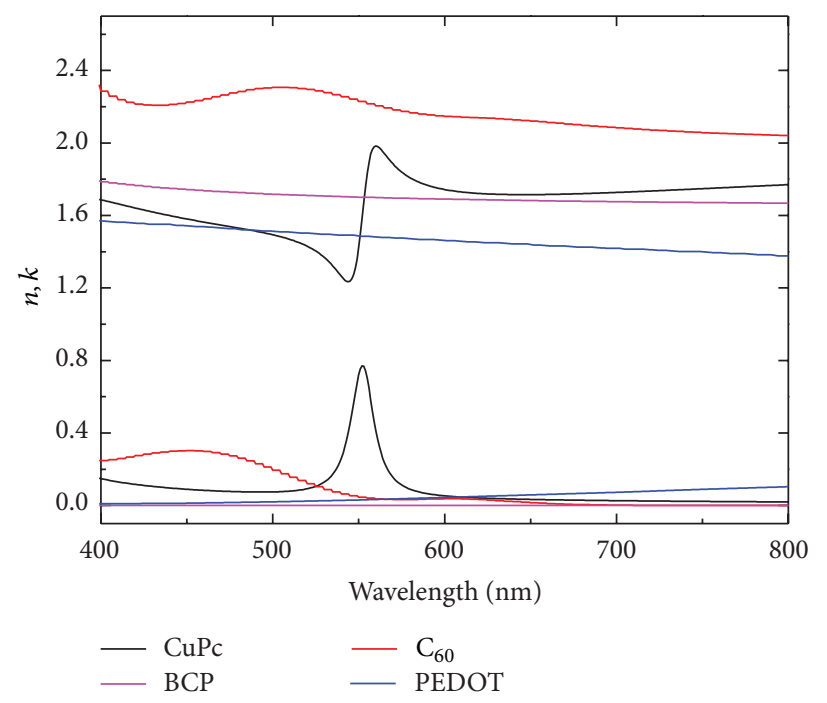

(a)

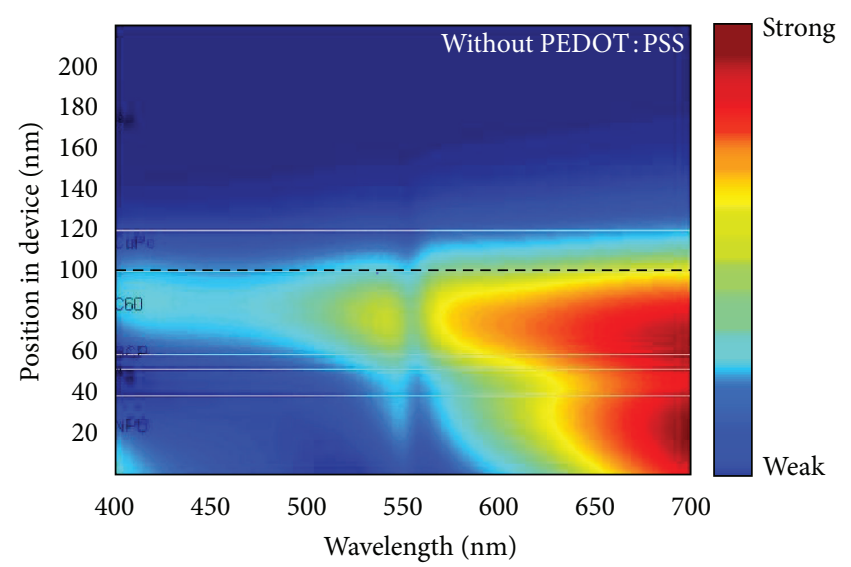

(b)

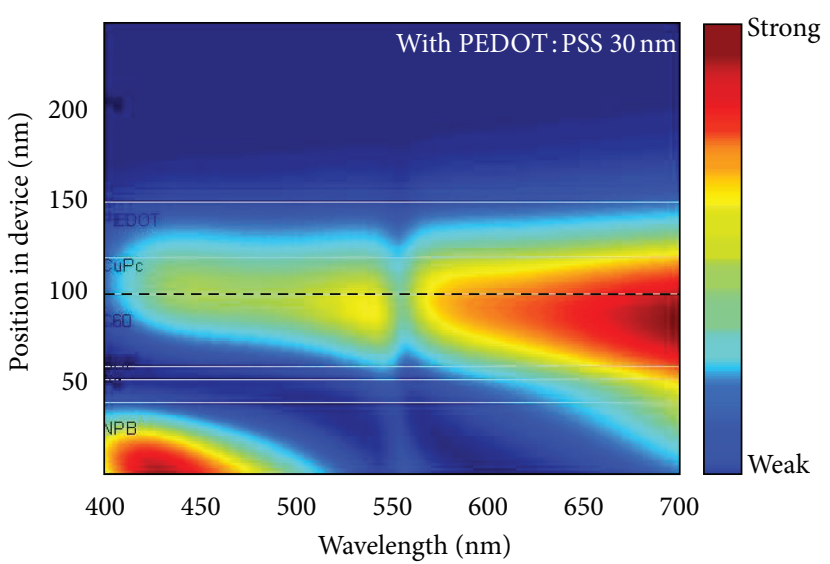

(c)

FiguRE 4: (a) Wavelength dependent refractive index $(n)$ and absorption coefficient $(k)$. Simulated optical field distribution inside TOPVs (b) with and (c) without $30 \mathrm{~nm}$ PEDOT:PSS layer.

field spectrum with a boundary near $550 \mathrm{~nm}$, dominated by the refractive index of the $\mathrm{CuPc}$ thin film. Comparing these two diagrams, the inserted PEDOT:PSS layer causes a rearrangement of the optical field. Also it is obvious to detect that the thickness of PEDOT:PSS is efficiently used to adjust the region of stronger optical field close to or far from the anode. In particular, the optical field intensity near the interface between donor $(\mathrm{CuPc})$ and acceptor $\left(\mathrm{C}_{60}\right)$ is the critical region to dissociate the excitons and determine the converted current. Here, the $30 \mathrm{~nm}$ PEDOT:PSS shifts the stronger optical field region (red part) towards the CuPc and $\mathrm{C}_{60}$ junction, reducing the exciton-loss in drift and increasing the probability of exciton dissociation. This implies that the device with $30 \mathrm{~nm}$ PEDOT:PSS has a higher converted current.

We used our series anodes to fabricate the TOPV devices. Figure 5 shows $J-V$ performances of the devices were measured in the dark. The control TOPV device without PEDOT:PSS indicates the best $J-V$ performance, caused by the short distance between anode and cathode.
For a fixed driving voltage, the small electrode separation distance produces the strong electrical field inside device and accelerates the carrier mobility of organic layers [42]. Although the PEDOT:PSS generally used to be the conducting polymer layer, its thickness is still a key factor in determining anisotropic layer conductivity [43, 44]. Sandwiching it in between two electrodes, bulk conduction of PEDOT:PSS layer diminishes as increasing film thickness. Hence, $1000 \mathrm{rpm}$ OPV device with the thickest PEDOT:PSS film presents a poor $J-V$ behavior. Decreasing PEDOT:PSS film thickness by rising spin speed improves bulk conduction and reduces the electrode separation distance, leading to the improvement in $J-V$ performance. However, the $7000 \mathrm{rpm}$ corresponding to a very thin film exhibits degrade $J-V$ performance. This is resulted from some defects on the film surface to hinder the carrier transport at the interface between anode and CuPc. Among these cases, the optimal spin speed is $5000 \mathrm{rpm}$ to form a PEDOT:PSS thin film with good conduction and smooth surface without defects. However, it is hard to avoid that an electrical lag exists 


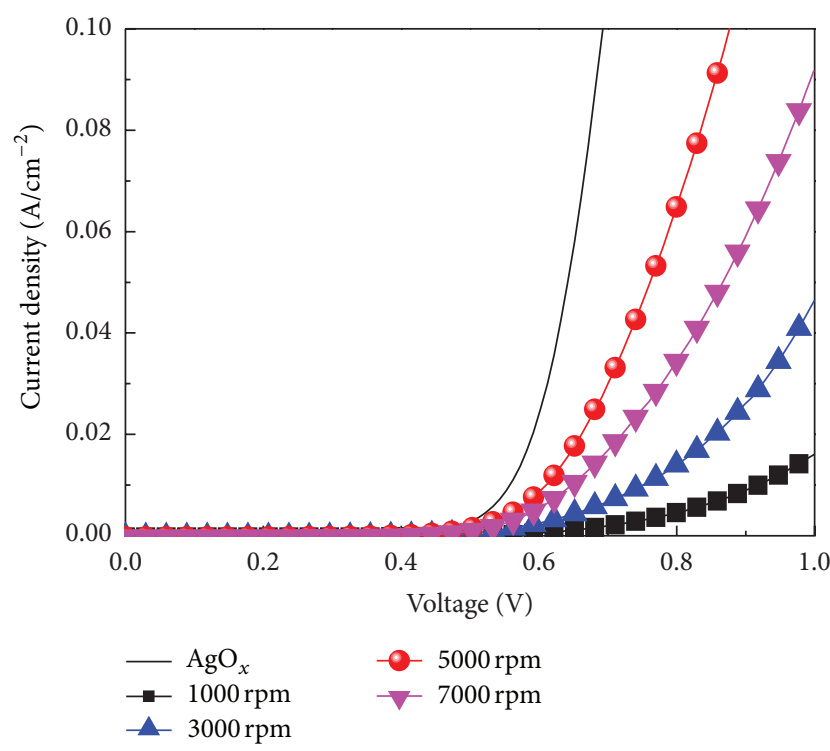

FIGURE 5: $J-V$ characteristics of TOPVs under darkness.

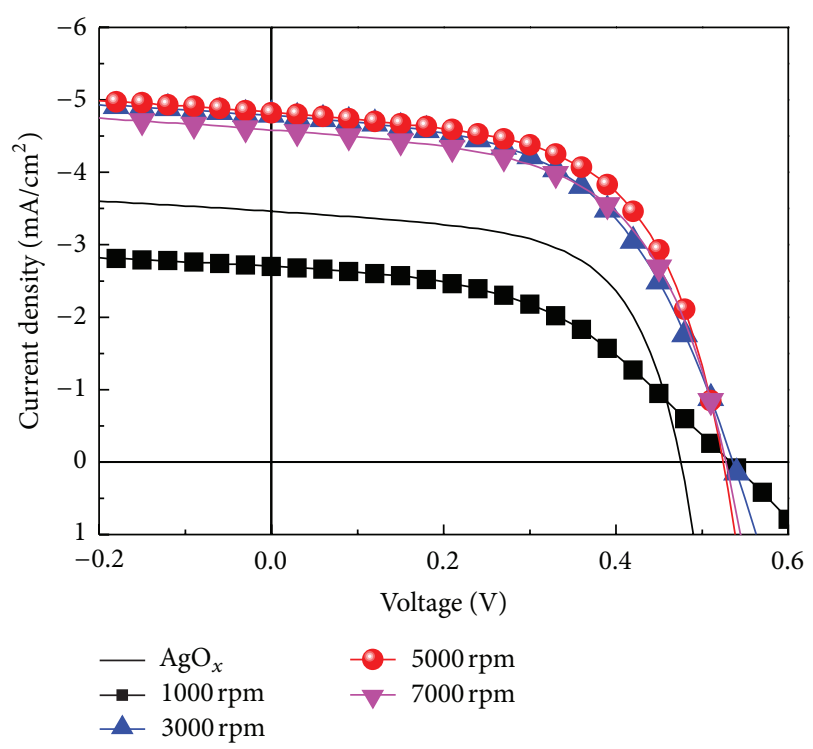

FIGURE 6: $J-V$ characteristics of TOPVs under AM1.5 solar simulator illumination.

between the optimal device and control device, due to the additional PEDOT:PSS layer.

Figure 6 illustrates $J$ - $V$ curves of OPV devices under AM1.5 solar simulator illumination. Table 1 lists the photovoltaic characterizations: open-circuit voltage $\left(V_{\mathrm{oc}}\right)$, shortcircuit current $\left(J_{\mathrm{sc}}\right)$, fill factor $(\mathrm{FF}), \mathrm{PCE}$, shunt resistor $\left(R_{\mathrm{sh}}\right)$, and series resistor $\left(R_{s}\right)$. The OPV devices incorporated with various PEDOT:PSS films have an almost identical $V_{\text {oc }}$ to each other $(0.53-0.54 \mathrm{~V})$. The $V_{\text {oc }}$ values are greater than $0.49 \mathrm{~V}$ as indicated for the control OPV device containing $\mathrm{Ag}-\mathrm{AgO}_{x}$ anode. The reason for this is that PEDOT:PSS has a greater work function than that of $\mathrm{AgO}_{x}$. Their $J_{\text {sc }}$ values are $2.74,4.77,4.8$, and $4.56 \mathrm{~mA} / \mathrm{cm}^{2}$ for $1000,3000,5000$, and $7000 \mathrm{rpm}$ fabrication spin speeds, respectively. As spin speed raises from 1000 to $5000 \mathrm{rpm}$, the diminishing film thickness results in enhanced $J_{\mathrm{sc}}$, because of the better bulk conduction of PEDOT:PSS film, the greater carrier mobility of organic layer, and the stronger optical filed intensity nears the exciton dissociation region. Distinctively, a degraded $J_{s c}$ obtained at $7000 \mathrm{rpm}$ device is resulted from the deteriorated hole collection induced by a few defects at the interface between $\mathrm{CuPc}$ and anode. Beyond $3000 \mathrm{rpm}$, OPV devices have greater $J_{\mathrm{sc}}$ values than $3.54 \mathrm{~mA} / \mathrm{cm}^{2}$ seen for control device because the presence of PEDOT:PSS reduced the energy barrier between organic layer and anode, benefits the hole transport at this interface, and moves the strong optical field close to exciton dissociation region. Furthermore, the reported effect of exciton quench close to the $\mathrm{Ag}$ anode is eliminated by incorporating a PEDOT:PSS layer. Taking into account FF, the control device has an excellent FF of $61.66 \%$ coming from the smallest $R_{s}$ and the largest $R_{\mathrm{sh}}$. Here, the FF is slightly affected by $R_{\mathrm{sh}}$, as the $R_{\mathrm{sh}}$ values are all greater than $1 \mathrm{k} \Omega \cdot \mathrm{cm}^{2}$; the difference in $R_{\mathrm{sh}}$ among these devices is negligible. Notably, $R_{s}$ is affected by the conduction of anode substrate to determine FF. Hence, the control device with the excellent conductor $\mathrm{Ag}-\mathrm{AgO}_{x}$ anode shows the smallest $R_{s}$ of $0.56 \Omega \cdot \mathrm{cm}^{2}$. The thinner PEDOT:PSS film performs the better bulk conduction to reduce the $R_{s}$ from 21.15 to $2.13 \Omega \cdot \mathrm{cm}^{2}$, except $7000 \mathrm{rpm}$ device with few defects on the PEDOT:PSS film surface. These defects hindered the carrier transport and lowered bulk conduction of the anode. Reasonably, $7000 \mathrm{rpm}$ device shows the increased $R_{s}$ behavior. Hence, the spin speed of $5000 \mathrm{rpm}$ is an optimal fabrication parameter for formation of buffer layer on the anode of TOPV device and provides the average PCE of $1.44 \%$ (maximum is $1.49 \%$ ). It is significant that 1.38 -fold PCE enhancement was obtained by inserting a PEDOT:PSS buffer layer between $\mathrm{AgO}_{x}$ and organic layer.

Figure 7 depicts the EQE spectra of devices and the absorption spectrum of $\mathrm{CuPc}$ and $\mathrm{C}_{60}$. It is clear that there are two divisions of each EQE spectrum individually mirroring the $\mathrm{CuPc}$ and $\mathrm{C}_{60}$ absorption band. Accordingly, it can be easily understood that the thickest case, $1000 \mathrm{rpm}$ device, shows the lowest EQE for the whole band. Excluding this worse case, the uniform PEDOT:PSS thin film obviously improves $\mathrm{EQE}$ at the $\mathrm{CuPc}$ band. The interface modification between $\mathrm{CuPc}$ and anode is responsible for observable improvement at $\mathrm{CuPc}$ band. Defects on the $7000 \mathrm{rpm}$ PEDOT:PSS surface indicate a small degradation at $\mathrm{CuPc}$ band. In this study, we did not have any modifications near the cathode. The EQE peak wavelength at $\mathrm{C}_{60}$ band blueshifts with decreasing PEDOT:PSS thickness, dominated by the cavity effect inside device in a manner similar to the description in Figure 4. The EQE amplitude at the $\mathrm{C}_{60}$ band is affected by the optical field distribution. $5000 \mathrm{rpm}$ device shows a better overall EQE spectrum, particularly for the $\mathrm{C}_{60}$ band. This device exhibits the greatest PCE of all devices.

\section{Conclusion}

In summary, we have successfully introduced PEDOT:PSS as an anode buffer layer to enhance the work function of 
TABle 1: Photovoltaic characteristics of TOPVs with various PEDOT:PSS thin films on $\mathrm{Ag}-\mathrm{AgO}$ anode.

\begin{tabular}{lccccrr}
\hline PEDOT:PSS & $V_{\mathrm{oc}}(\mathrm{V})$ & $J_{\mathrm{sc}}\left(\mathrm{mA} / \mathrm{cm}^{2}\right)$ & FF $(\%)$ & Eff $(\%)$ & $R_{\mathrm{sh}}\left(\mathrm{k} \Omega * \mathrm{~cm}^{2}\right)$ & $R_{s}\left(\Omega * \mathrm{~cm}^{2}\right)$ \\
\hline UVO $45 \mathrm{~s}$ & $0.48 \pm 0.01$ & $3.54 \pm 0.02$ & $61.66 \pm 0.18$ & $1.08 \pm 0.02$ & $1.36 \pm 0.02$ & $0.56 \pm 0.2$ \\
$1000 \mathrm{rpm}$ & $0.54 \pm 0.01$ & $2.74 \pm 0.04$ & $45.71 \pm 0.15$ & $0.69 \pm 0.02$ & $1.48 \pm 0.02$ & $21.15 \pm 2.51$ \\
$3000 \mathrm{rpm}$ & 0.54 & $4.77 \pm 0.05$ & $52.26 \pm 0.82$ & $1.36 \pm 0.02$ & $1.12 \pm 0.05$ & $7.47 \pm 1.1$ \\
$5000 \mathrm{rpm}$ & $0.53 \pm 0.01$ & $4.8 \pm 0.05$ & $58.4 \pm 0.38$ & $1.44 \pm 0.05$ & $1.08 \pm 0.01$ & $2.13 \pm 0.8$ \\
$7000 \mathrm{rpm}$ & 0.53 & $4.56 \pm 0.02$ & $57.41 \pm 0.24$ & $1.39 \pm 0.01$ & $1.14 \pm 0.06$ & $3.69 \pm 0.13$ \\
\hline
\end{tabular}

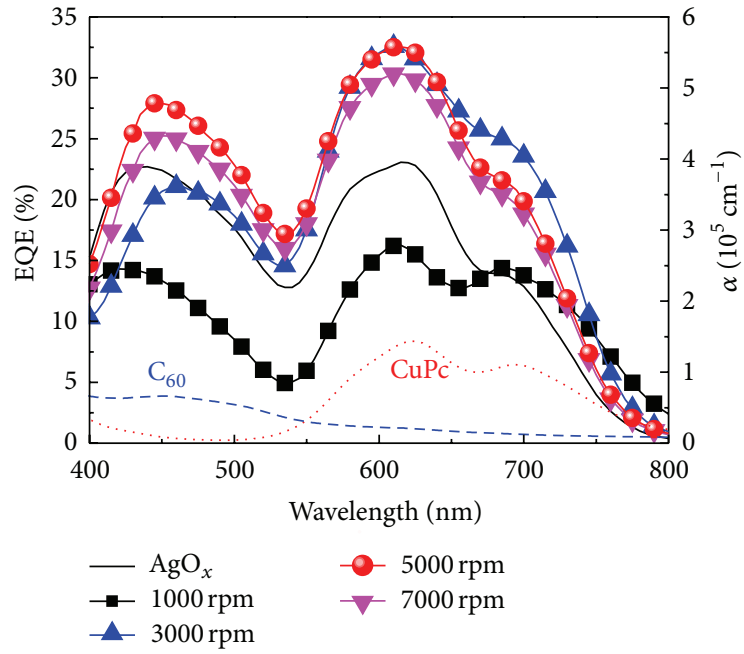

FIGURE 7: EQE spectra of TOPVs and absorption spectra of $\mathrm{CuPc}$ and $\mathrm{C}_{60}$.

Ag anode and then eliminated the energy barrier between organic layer and anode, thereby preventing the anode quenching and enhancing the $J_{\mathrm{sc}}$ for TOPV device. After characterizing PEDOT:PSS layers fabricated at various spin speeds, the optimal film thickness $\sim 30 \mathrm{~nm}$ with good morphological quality could be obtained at $5000 \mathrm{rpm}$. In particular, a great enhancement in $J_{\text {sc }}$ was observed by assembling the TOPV device with a PEDOT:PSS buffer layer fabricated at this optimal spin parameter. The optimized device offered a 1.37-fold enhancement in PCE compared to that of OPV without a buffer layer.

\section{Acknowledgments}

The authors acknowledge with great appreciation the financial support provided by the National Science Council (NSC), R.O.C. under Grant nos. 102-2221-E-155-047, 102-2622-E155-008-CC3, and Bureau of Energy, Ministry of Economic Affairs, R.O.C. under Grant no. 102-E0616.

\section{References}

[1] C. W. Tang, “Two-layer organic photovoltaic cell," Applied Physics Letters, vol. 48, no. 2, article 183, 3 pages, 1986.

[2] B. A. Gregg and M. C. Hanna, "Comparing organic to inorganic photovoltaic cells: theory, experiment, and simulation," Applied Physics Letters, vol. 93, no. 6, article 3605, 10 pages, 2003.
[3] B. P. Jelle, C. Breivik, and H. D. Rkenes, "Building integrated photovoltaic products: a state-of-the-art review and future research opportunities," Solar Energy Materials and Solar Cells, vol. 100, pp. 69-96, 2012.

[4] R. Po, C. Carbonera, A. Bernardi, F. Tinti, and N. Camaioni, "Polymer- and carbon-based electrodes for polymer solar cells: toward low-cost, continuous fabrication over large area," Solar Energy Materials and Solar Cells, vol. 100, pp. 97-114, 2012.

[5] P. Peunmans, A. Yakimov, and S. R. Forrest, "Small molecular weight organic thin-film photodetectors and solar cells," Journal of Applied Physics, vol. 93, no. 7, article 3693, p. 31, 2003.

[6] R. Schueppel, R. Timmreck, N. Allinger et al., "Controlled current matching in small molecule organic tandem solar cells using doped spacer layers," Journal of Applied Physics, vol. 107, no. 4, Article ID 044503, 2010.

[7] N. Espinosa, M. Hösel, D. Angmo, and F. C. Krebs, "Solar cells with one-day energy payback for the factories of the future," Energy and Environmental Science, vol. 5, no. 1, pp. 5117-5132, 2012.

[8] C. F. Lin, M. Zhang, S. W. Liu, T. L. Chiu, and J. H. Lee, "High photoelectric conversion efficiency of metal phthalocyanine/fullerene heterojunction photovoltaic device," International Journal of Molecular Sciences, vol. 12, no. 1, pp. 476-505, 2011.

[9] C. F. Lin, S. W. Liu, C. C. Lee et al., "Open-circuit voltage and efficiency improvement of subphthalocyanine-based organic photovoltaic device through deposition rate control," Solar Energy Materials and Solar Cells, vol. 103, pp. 69-75, 2012.

[10] B. Kippelen and J. L. Brédas, Energy \& Environmental Science, vol. 2, no. 3, pp. 251-261, 2009.

[11] B. B. Yang, D. D. Zhang, S. T. Lee, Y. Q. Li, and J. X. Tang, "Efficiency enhancement of organic photovoltaic devices using a Sm:Al compound electrode," Applied Physics Letters, vol. 102, no. 7, Article ID 073301, 4 pages, 2013.

[12] F. C. Krebs, "Roll-to-roll fabrication of monolithic large-area polymer solar cells free from indium-tin-oxide," Solar Energy Materials and Solar Cells, vol. 93, no. 9, pp. 1636-1641, 2009.

[13] F. C. Krebs, "All solution roll-to-roll processed polymer solar cells free from indium-tin-oxide and vacuum coating steps," Organic Electronics, vol. 10, no. 5, pp. 761-768, 2009.

[14] J. Meiss, M. K. Riede, and K. Leo, "Towards efficient tin-doped indium oxide (ITO)-free inverted organic solar cells using metal cathodes," Applied Physics Letters, vol. 94, no. 1, Article ID 013303, 3 pages, 2009.

[15] M. Manceau, D. Angmo, M. Jørgensen, and F. C. Krebs, "ITOfree flexible polymer solar cells: from small model devices to roll-to-roll processed large modules," Organic Electronics, vol. 12, no. 4, pp. 566-574, 2011.

[16] R. Søndergaard, M. Hösel, D. Angmo, T. T. Larsen-Olsen, and F. C. Krebs, "Roll-to-roll fabrication of polymer solar cells," Materialtoday, vol. 15, p. 36, 2012. 
[17] F. C. Krebs, J. Fyenbo, and M. Jørgensen, "Product integration of compact roll-to-roll processed polymer solar cell modules: methods and manufacture using flexographic printing, slotdie coating and rotary screen printing," Journal of Materials Chemistry, vol. 20, pp. 8994-9001, 2010.

[18] F. C. Krebs, "Fabrication and processing of polymer solar cells: a review of printing and coating techniques," Solar Energy Materials and Solar Cells, vol. 93, no. 4, pp. 394-412, 2009.

[19] H. W. Lin, S. W. Chiu, L. Y. Lin et al., "Device engineering for highly efficient top-illuminated organic solar cells with microcavity structures," Advanced Materials, vol. 24, no. 17, pp. 2269-2272, 2012.

[20] B. Kouskoussa, M. Morsli, K. Benchouk et al., "On the improvement of the anode/organic material interface in organic solar cells by the presence of an ultra-thin gold layer," Physica Status Solidi A, vol. 206, no. 2, pp. 311-315, 2009.

[21] H. Jin, C. Tao, M. Velusamy et al., "Efficient, large area ITOand-PEDOT-free organic solar cell sub-modules," Advanced Materials, vol. 24, no. 19, pp. 2572-2577, 2012.

[22] S. D. Yambem, K.-S. Liao, N. J. Alley, and S. A. Curran, "Stable organic photovoltaics using Ag thin film anodes," Journal of Materials Chemistry, vol. 22, no. 14, pp. 6894-6898, 2012.

[23] S. I. Na, S. S. Kim, J. Jo, and D. Y. Kim, "Efficient and flexible ITO-free organic solar cells using highly conductive polymer anodes," Advanced Materials, vol. 20, no. 21, pp. 4061-4067, 2008.

[24] C. F. Lin, S. W. Liu, W. F. Hsu et al., "Modification of silver anode and cathode for a top-illuminated organic photovoltaic device," Journal of Physics D, vol. 43, no. 39, Article ID 395101, 2010.

[25] M. Zhang, T. L. Chiu, C. F. Lin, J. H. Lee, J. K. Wang, and $\mathrm{Y}$. Wu, "Roughness characterization of silver oxide anodes for use in efficient top-illuminated organic solar cells," Solar Energy Materials and Solar Cells, vol. 95, no. 9, pp. 2606-2609, 2011.

[26] V.-E. Choong, Y. Park, N. Shivaparan, C. W. Tang, and Y. Gao, "Deposition-induced photoluminescence quenching of tris-(8hydroxyquinoline) aluminum," Applied Physics Letters, vol. 71, no. 8, pp. 1005-1007, 1997.

[27] T. L. Chiu, W. F. Xu, C. F. Lin, J. H. Lee, C. C. Chao, and M. K. Leung, "Optical and electrical characteristics of Ag-doped perylene diimide derivative," Applied Physics Letters, vol. 94, no. 1, Article ID 013307, 3 pages, 2009.

[28] Y. Wu, H. R. Wu, M. L. Wang et al., "Metal-induced photoluminescence quenching in thin organic films originating from noncontact energy transfer between single molecule and atom," Applied Physics Letters, vol. 90, Article ID 154105, 3 pages, 2007.

[29] M. Y. Chan, C. S. Lee, S. L. Lai et al., "Efficient organic photovoltaic devices using a combination of exciton blocking layer and anodic buffer layer," Journal of Applied Physics, vol. 100, no. 9, Article ID 094506, 2006.

[30] D. W. Zhao, P. Liu, X. W. Sun et al., "An inverted organic solar cell with an ultrathin $\mathrm{Ca}$ electron-transporting layer and $\mathrm{MoO}_{3}$ hole-transporting layer," Applied Physics Letters, vol. 95, no. 15, Article ID 153304, 3 pages, 2009.

[31] M. Vogel, S. Doka, C. Breyer, M. C. Lux-Steiner, and K. Fostiropoulos, "On the function of a bathocuproine buffer layer in organic photovoltaic cells," Applied Physics Letters, vol. 89, no. 16, Article ID 163501, 2006.

[32] D. Kabra, M. H. Song, B. Wenger, R. H. Friend, and H. J. Snaith, "High efficiency composite metal oxide-polymer electroluminescent devices: a morphological and material based investigation," Advanced Materials, vol. 20, no. 18, pp. 34473452, 2008.
[33] Y. Park, V.-E. Choong, B. R. Hsieh, C. W. Tang, and Y. Gao, "Gap-state induced photoluminescence quenching of phenylene vinylene oligomer and its recovery by oxidation," Physical Review Letters, vol. 78, no. 20, pp. 3955-3958, 1997.

[34] J. Mei, M. S. Bradley, and V. Bulović, "Photoluminescence quenching of tris-(8-hydroxyquinoline) aluminum thin films at interfaces with metal oxide films of different conductivities," Physical Review B, vol. 79, no. 23, Article ID 235205, 8 pages, 2009.

[35] D. L. Smith, Thin-Film Disposition Principles and Practice, McGraw-Hill, New York, NY, USA, 1995.

[36] S. Khodabakhsh, B. M. Sanderson, J. Nelson, and T. S. Jones, "Using self-assembling dipole molecules to improve charge collection in molecular solar cells," Advanced Functional Materials, vol. 16, no. 1, pp. 95-100, 2006.

[37] M. Massi, M. Cavallini, and F. Biscarini, "Influence of the substrate hydrophilicity on the grid assisted deposition of tris-(8-hydroxyquinolinato) aluminum(III) thin films," Surface Science, vol. 603, no. 3, pp. 503-506, 2009.

[38] C. Cioarec, P. Melpignano, N. Gherardi, R. Clergereaux, and C. Villeneuve, "Ultrasmooth silver thin film electrodes with high polar liquid wettability for OLED microcavity application," Langmuir, vol. 27, no. 7, pp. 3611-3617, 2011.

[39] G. F. Burkhard, E. T. Hoke, and M. D. McGehee, "Accounting for interference, scattering, and electrode absorption to make accurate internal quantum efficiency measurements in organic and other thin solar cells," Advanced Materials, vol. 22, no. 30, pp. 3293-3297, 2010.

[40] R. Häusermann, E. Knapp, M. Moos, N. A. Reinke, T. Flatz, and B. Ruhstaller, "Coupled optoelectronic simulation of organic bulk-heterojunction solar cells: parameter extraction and sensitivity analysis," Journal of Applied Physics, vol. 106, no. 10, Article ID 104507, 9 pages, 2009.

[41] F. Deschler, D. Riedel, B. Ecker, E. Hauff, E. D. Como, and R. C. I. MacKenzi, "Increasing organic solar cell efficiency with polymer interlayers," Physical Chemistry Chemical Physics, vol. 15, no. 3, pp. 764-769, 2013.

[42] S. C. Tse, S. W. Tsang, and S. K. So, "Polymeric conducting anode for small organic transporting molecules in dark injection experiments," Journal of Applied Physics, vol. 100, no. 6, Article ID 063708, 5 pages, 2006.

[43] A. M. Nardes, M. Kemerink, and R. A. J. Janssen, "Anisotropic hopping conduction in spin-coated PEDOT:PSS thin films," Physical Review B, vol. 76, no. 8, Article ID 085208, 7 pages, 2007.

[44] Y. H. Kim, C. Sachse, M. L. Machala, C. May, L. MüllerMeskamp, and K. Leo, "Highly conductive PEDOT:PSS electrode with optimized solvent and thermal post-treatment for ITO-free organic solar cells," Advanced Functional Materials, vol. 21, no. 6, pp. 1076-1081, 2011. 

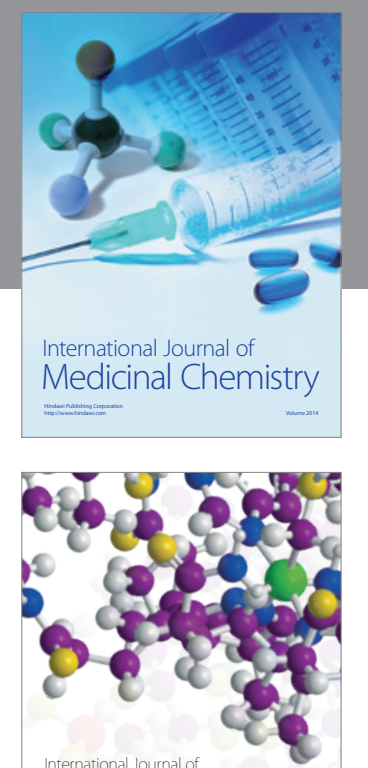

\section{Carbohydrate} Chemistry

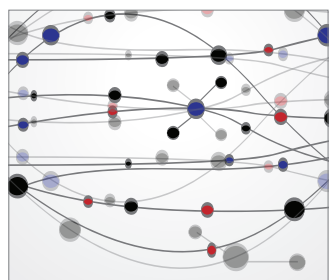

The Scientific World Journal
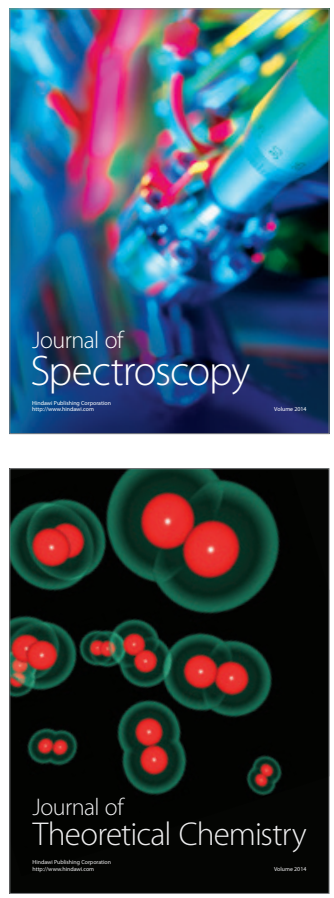
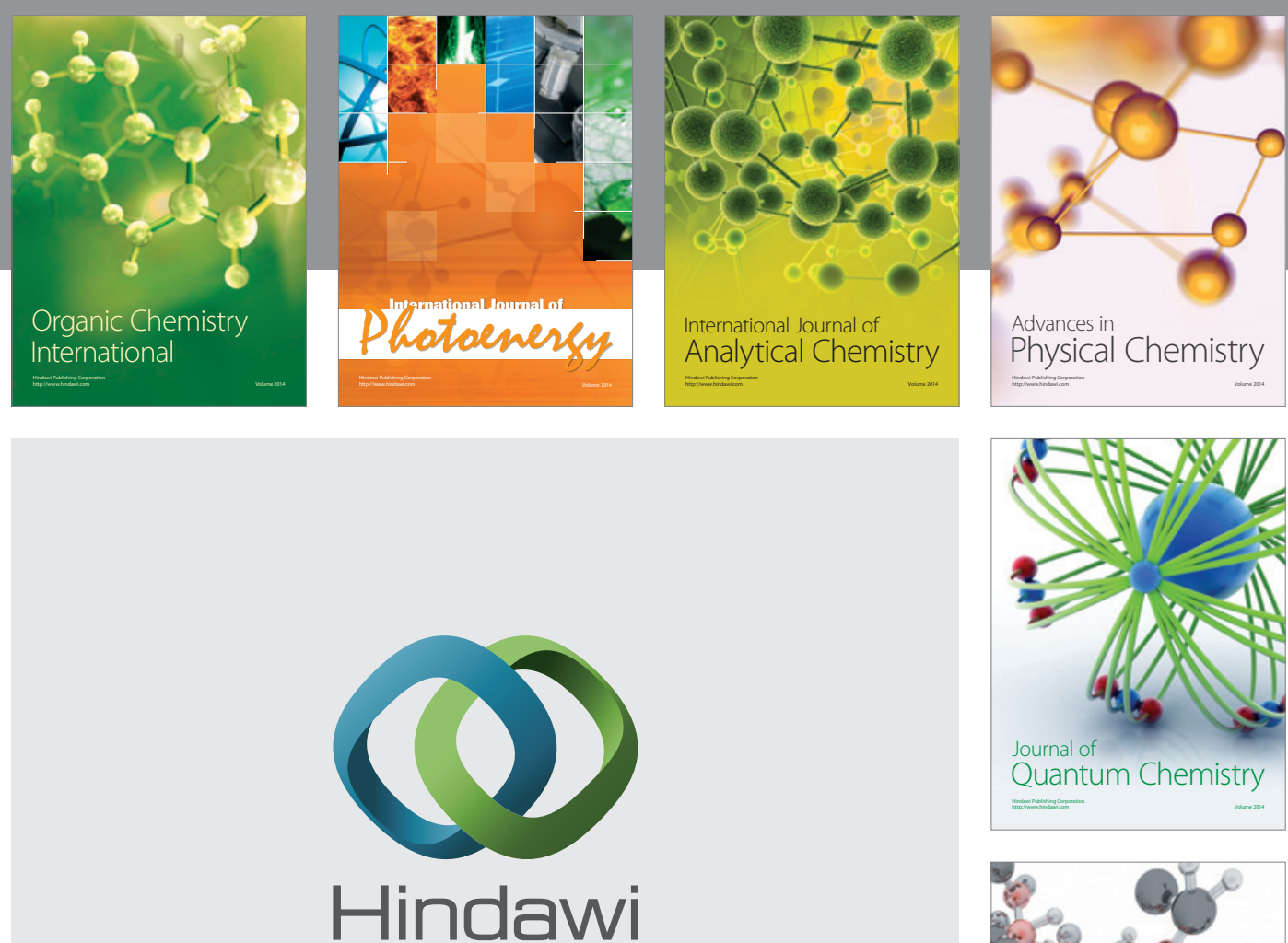

Submit your manuscripts at

http://www.hindawi.com

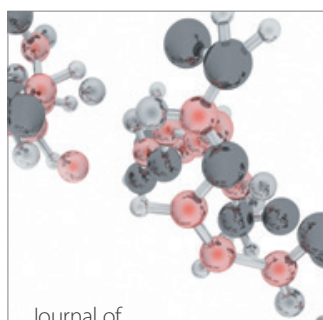

Analytical Methods

in Chemistry

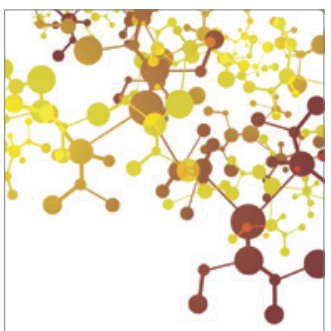

Journal of

Applied Chemistry

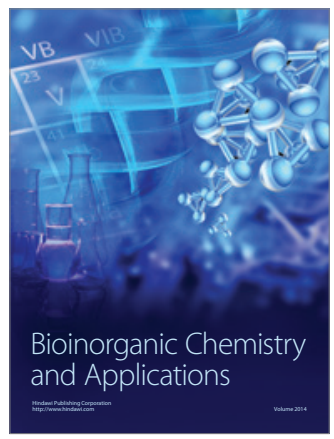

Inorganic Chemistry
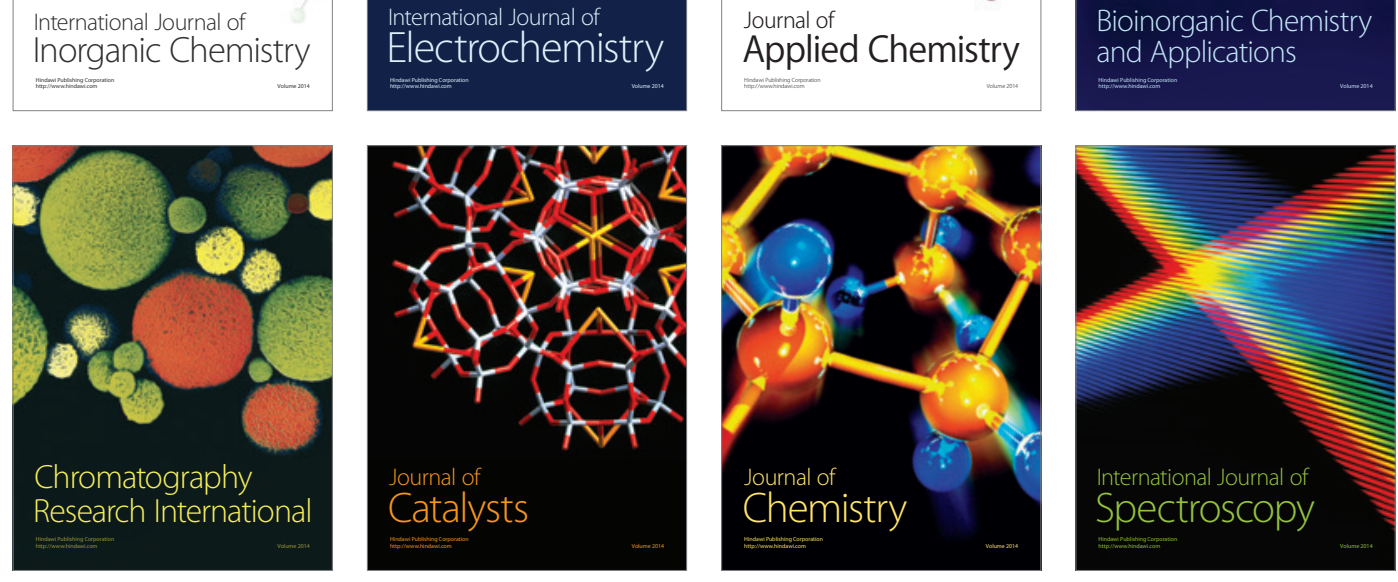